of the orbital rim. The external rectus belly and the periosteum were retracted upwards, and with a blunt dissector the orbital fat was gently separated to expose the neoplasm which lay within the muscle cone below the optic nerve and mainly on its temporal side. The optic nerve was stretched over the neoplasm and displaced upwards and inwards. The neoplasm was greyish-blue, had a smooth surface, was not attached to the globe, and tapered posteriorly towards the apex of the orbit. It was defined by gentle blunt dissection mainly with the gloved forefinger. There was some difficulty in freeing its posterior extremity. Fig. 1 (Special Plate) is a photograph of the neoplasm.

The lateral wall of the orbit was now replaced by a non-touch technique, holding the bone in forceps. The orbital periosteum and temporal muscle fell back into their normal positions. A split rubber drain was passed into the orbit at the junction of the lateral wall and the floor, and another was laid over the temporal fascia parallel to the horizontal incision and emerging from its posterior extremity. The incision was repaired in two layers, the fat and subcutaneous tissues being sewn up with inverted interrupted catgut sutures and the skin edges with interrupted sutures of number 00 black silk placed $2 \mathrm{~mm}$. from the edge of the incision and $3 \mathrm{~mm}$. apart. Vaselined gauze covered the wound, and a pressure dressing was applied over this.

Pathological Report.-The neoplasm measured 30 by 23 by $16 \mathrm{~mm}$. After removal it was yellowish-white in colour and had a smooth glistening surface and a rubbery consistence. Dr. H. F. Brewer's histological report was as follows: "The specimen was a circumscribed tumour of firm consistence and of oval shape, $30 \mathrm{~mm}$. in its longest diameter by $23 \mathrm{~mm}$. by $16 \mathrm{~mm}$. The approximate weight was $5.5 \mathrm{~g}$. (Fig. 1). It was enclosed in a fibrous capsule which appeared to have ruptured at one point. The cut surface had a yellowish-white translucent appearance. Section shows that the tumour consists of a loosely woven tissue in which spindle-shaped cells, the nuclei of which are narrow and slightly curved, run in an irregular interlacing fashion. In the central part there is extensive collagenous change in the stroma ; in another small area the tumour is very cellular, but not of a degree to suggest a sarcomatous change. There is a scattered infiltration by small lymphocytes and the tumour is surrounded by a capsule. No nerve elements are recognizable, but the histological and clinical features point to the tumour being a neurofibroma" (Fig. 2, Special Plate).

Post-operative Course.- The drainage tubes were removed 48 hours after operation. The wound healed by first intention. and the lateral wall of the orbit united to adjacent bones in its normal position. The scar of the incision is scarcely visible. Papilloedema was subsiding on the fourth day after operation and had disappeared by the tenth day. Proptosis subsided, but the left eye has remained higher than the right, possibly the transfrontal craniotomy and the removal of the orbital roof may be factors in causing this. There remains slight limitation of action of the external rectus. but all other ocular movements are normal. There is some dusky crimson discoloration around the left macula. Left vision has recovered to $6 / 6$, with $-5.25 \mathrm{D}$ sphere, and the visual field has improved by $35^{\circ}$ in the lower half, where the main defect was present before operation.

\section{Summary and Conclusion}

A case is described of unilateral proptosis due to a neurofibroma 30 by 23 by $16 \mathrm{~mm}$. situated within the cone of the recti muscles and beneath the optic nerve. Transfrontal craniotomy had failed to reveal the neoplasm which was removed six months later, after temporary removal of the lateral orbital wall. Vision recovered from hand movements to $6 / 6$, and the visualfield defect improved by $35^{\circ}$.

This case illustrates the value of exploration of the orbit in cases where a neoplasm is suspected as the cause of unilateral proptosis. It shows also that when the neoplasm is limited to the orbital contents and lies behind the eye, the orbit may be effectively explored after temporary removal of the lateral orbital wall. I think this approach route is preferable to transfrontal craniotomy.

\section{REFERENCES}

Dandy, W. E. (1943). Orbital Tumours, London.

Drell, M. (1944). Amer. J. Ophthal.. 27, 543

Jackson, Harvey (1945). Proc, roy Soc. Med. 38, 587.

Stallard, H. B. (1938). Lancet, 1, 131.

- (1946). Eye Surgery. John Wright \& Son.

\section{LIPOID PNEUMONIA: A PITFALL IN DIAGNOSIS}

\author{
BY
}

R. E. REWELL, M.D., M.R.C.P.

Pathologist to the Zoological Society of London

(From the Department of Pathology, Guy's Hospital Medical School)

[With Photogravure Plate]

Changes in the lung produced by the introduction of oils appear to have been infvestigated first by Guieysse-Pellissier (1920), who injected olive oil into the trachea of the dog and the rabbit and found it to be removed from the alveoli by phagocytes without leaving any trace. The process was hastened if tubercle bacilli were ground up in the oil. Corper and Freed (1922) in an investigation of oils then commonly applied to the upper respiratory tract for therapeutic purposes, found that " proliferative bronchopneumonia "followed the introduction of chaulmoogra oil, olive oil, or petrolatum into the lung of the rabbit. Laughlen (1925) reported three cases with the lesions now known to be typical of lipoid pneumonia-two infants receiving liquid paraffin as nasal drops and a man of 37 with "multiple paralyses" taking it by mouth. He attempted to reproduce the condition experimentally, but killed his animals (rabbits) while the lesions were still in their early stages. Pinkerton (1927) reported similar cases, and in 1928 he published the results of experiments designed to discover an oil suitable as a base for the introduction of radioopaque substances into the lungs. In the course of these experiments he made a thorough investigation of the illeffects produced by some. He found that when vegetable cils were introduced they produced no tissue reaction and were expectorated in a few days, leaving no trace. Animal oils, however, were first emulsified in situ and later attacked by phagocytes. Some of these reached the lymph nodes where fibrosis was set up after two or three months, but others remained in the lumina of the alveoli where the same process occurred. Foreign-body giant cells arose in both sites. Fatty acids produced by hydrolysis were the irritative agents, the total damage that resulted depending on the proportion of free fatty acids present in the original oil and on the rate of its hydrolysis. Chaulmoogra oil was unique in producing acute tissue necrosis from the start. Mineral oils were not hydrolysed; they produced an immediate phagocyte response in the alveolus and were rapidly emulsified. The droplets were transferred to the lymph nodes, but here and in the alveoli fibrous tissue reaction followed far more slowly than with animal oils. In contradistinction to vegetable oils, however, the formation of fibrous tissue was inevitable eventually.

Since these studies several series of cases have been described (Ikeda, 1937; Paterson, 1938; Graef, 1939 ; Young, Applebaum, and Wasserman, 1939; and Pinkerton and Moragues, 1940). All these except one occurred in infants or in debilitated, aged, or paralysed people who were taking animal or mineral oil by mouth or as nasal drops : the exception was an apparently healthy young woman who was taking cod-liver oil by mouth (Young, Applebaum, and Wasserman, 1939). It is noticeable that only the series of Paterson seems to have been reported in this country, which is surprising in view of the fact that he found as many as eight cases in 813 consecutive necropsies at a general hospital.

The gross lesions reported in the lungs vary from a generalized consolidation by greasy material resembling red hepatization to local areas of fibrosis surrounding a mass 
of necrotic tissue and oil which ranges in size from a milium to a "paraffinoma" several centimetres across. Several observers record fibrotic nodules resembling milia in other organs-for example, in liver, lung, and spleen by Pinkerton and Moragues, and in kidneys, adrenals, and ovaries by Young, Applebaum, and Wasserman. These last observers found the fibrosis to be so extensive as to produce arteritis and periarteritis in the kidney, with considerable glomerular damage. In nearly all these cases the diagnosis was unsuspected during life. Where trouble in the chest was suspected (Graef, 1939), radiographs showed shadows near the hilus of the posterior dependent parts, and these did not alter in appearance over some months. Most of the cases were discovered at necropsy, and the cause of death had generally been considered on clinical grounds to be due to other causes. In many the lipoid pneumonia may well have been of only minor importance.

The following case, showing many of the typical features described above, occurred in a healthy young woman from whom no history of the ingestion or aspiration of an oil was ever obtained, and it emphasizes the difficulties in the diagnosis of such a case.

\section{Case Report}

The patient was a healthy and intelligent member of the Women's Land Army, aged 19 at the time of death. She was admitted to hospital on July 4, 1945, with an acute febrile illness resembling rheumatic fever with erythema nodosum. Nothing abnormal was found on clinical examination of the chest, cardiovascular system, or the abdomen. The temperature was $100.2^{\circ}$ F. $\left(37.9^{\circ} \mathrm{C}\right.$.) the pulse 120 , and the respirations 22 . The fauces were injected, and there were raised red patches on the legs. She did not complain of cough.

A radiograph of the chest (Fig. 1, Special Plate) showed a collapsed right middle lobe and enlarged mediastinal lymph nodes. The patient recovered quickly from her acute episode, and the patches on the legs cleared up. The blood picture was normal, the radiographic appearances were unlike tubercle, and the sputum was repeatedly "negative," and so, by exclusion, a diagnosis of Hodgkin's disease was made, a reticulo-endotheliosis being the only plausible explanation that could be found for enlarged mediastinal lymph nodes in a young woman without changes in the lung fields. Two courses of deep therapy were given without producing any marked change in the mediastinal shadows.

The patient was readmitted on April 30, 1946. She was dyspnoeic, with enlarged neck veins and shallow respirations. The percussion note over both upper zones of the chest was impaired and bronchial breathing was heard there. Radiographs showed an increased mediastinal shadow and infiltrations near the lung roots (Fig. 2, Special Plate). She died on May 12.

Findings at Necropsy.-Recent fibrinous exudate extended all over the pericardial surfaces and a little excess of fluid was present in loculi among this. The air-passages were all acutely inflamed. A small quantity of clear fluid was free in each pleural sac, but the serous surfaces were normal All the mediastinal lymph nodes were enlarged, forming a dense mass which surrounded the main bronchi and compressed them to a moderate degree. The nodes were discrete, but bound together by much fibrous tissue. Their substance was firm, quite uniform in consistency and appearance, and of a definite pinkish tinge. No normal lymphoid tissue appeared to remain at all. The lungs were firm and solid, especially in the upper lobes. No discrete nodules appeared on their surfaces. On gross section the upper lobes were seen to be infiltrated extensively by firm pinkish material which was most abundant near the hilum and appeared to spread out in tentacles through the upper lobes. Its cut surface was quite dry, was certainly not greasy, and showed no sign of breaking down or of surrounding inflammation. Many circumscribed patches of the same appearance lay in the lower lobes. The intervening lung substance revealed oedema but no obvious bronchopneumonia ; there were no areas of collapse and no abscesses. The spleen showed prominent follicles but no obvious infiltration. The liver showed anly chronic passive congestion. The uterus was menstruating. No other abnormalities were found in any system.

Histological Appearances.-Sections of the lungs prepared from material embedded in paraffin revealed an intense histiocytic activity throughout the alveoli. Many macrophages lay free in the lumina, the cytoplasm of the majority being distended and of a foamy appearance. The endothelium of the alveoli had been shed and fibrous tissue surrounded the macrophages in the lumina, but the extent to which this had taken place varied much throughout the sections. Fig. 3 (Special Plate) shows a typical area. In frozen section the macrophages were seen to be distended with fat globules which stained with scarlet red (Fig. 4, Special Plate). Unfortunately the true nature of the condition was not understood at necropsy, so that sufficient material to identify the fat by differential staining was not saved. In the mediastinal lymph nodes the fat globules were again obvious in frozen sections. Intense histiocytic activity and formation of fibrous tissue were evident and giant cells of the "foreign-body" type were numerous (Fig. 5, Special Plate). Very similar areas were seen in the spleen and liver. These were small, and superficially they resembled tuberculous milia, but on close examination they were seen to contain phagocytes instead of epitheloid cells and the giant cells were once more of the foreign-body type (Figs. 6 and 7, Special Plate).

\section{Discussion}

Origin of the Oil.-Careful inquiries were made of the patient's family, friends, employers, and medical attendants to discover whether or not she had come into contact with any oil either as nasal drops, or by mouth, or as a spray in connexion with her work, but no evidence whatsoever was obtained that she had used any such substance.

The Differential Diagnosis.-The diagnosis of lipoid pneumonia would be difficult in the absence of an obvious history of ingestion or inhalation of an oil or fat, especially in a healthy adult. In the above case the early enlargement of the mediastinal lymph nodes in the absence of lung shadows was highly suggestive of Hodgkin's disease, especially with a normal blood picture. As the response to treatment with radiation was so poor, this diagnosis might have been reconsidered, but few alternatives presented themselves, and none with a better prognosis.

The Genesis of the Lesions.-In the above case the great outpouring of phagocytes into the alveoli would seem to indicate that the condition was due to a mineral oil, as found by Pinkerton (1928) and quoted above. The fibrous tissue present in the lung was more abundant than in Pinkerton's cases of this type, but it may well have been due to the deep therapy. However, such fibrosis did develop in his cases eventually. Although developed in response to a chemical irritant, this fibrous tissue has none of the specific character as is seen, for example, in silicosis. The degree of fibrosis developed in other tissues would not seem to depend so much on the nature of the irritant. It is noteworthy that similar lesions may arise in lymph nodes where excess of fat is present from causes other than inhalation. Thus Hill (1937) and Glynn and Rosenheim (1938) found fibrosis and foreign-body giant cells round masses of fat accumulated in the abdominal lymph nodes in steatorrhoea, while Vaux (1943) found foamy macrophages in what may have been earlier lesions of the same nature. It is evident, then, that such irritation may accompany the presence of fat in lymph nodes and may be responsible for the lymphatic obstruction in the sprue syndrome. It may be part of a vicious circle in which more and more fibrosis would lead to the progressive accumulation of fat.

\section{Summary}

A case of lipoid pneumonia in a young woman is described. The origin of the inhaled oil is uncertain. The condition is more common than is often supposed and should be considered 
as a diagnosis in any case where chronic infiltration of the lung fails to respond to treatment.

The pathology is that of a chronic response to irritation and is produced by animal or mineral cils. In the former case hydrolysis of the oil to fatty acids leads to more rapid development of fibrosis than in the latter. Similar appearances may be seen in the lymph nodes of this condition and of sprue, and it is suggested that they may be of similar origin.

I have to thank Dr. W. Lindsay Locke for the radiographs, Mr. J. F. Carter Braine, Dr. Locke, and Dr. P. R. C. Evans for permission to publish the clinical notes, and Messrs. Ilfords for the photographs.

\section{RefERENCES}

Corper, H. J., and Freed, H. (1922). J. Amer. med. Ass., 79, 1739. Glynn, L. E., and Rosenheim, M. L. (1938). J. Path. Bact., 47, 285. Graef, I. (1939). Arch. Pathol., 28, 613.

Guieysse-Pellissier, A. (1920). C. r. Soc. Biol., Paris, 83, 809, 1137. Hill, J. M. (1937). Amer. J. Paih., 13, 267.

lkeda, K. (1937). Arch. Pathol., 23, 470.

Laughlen, G. F. (1925). Amer. J. Path., 1, 407.

Paterson, J. L. H. (1938). J. Path. Bact. 46, 151

Pinkerton, H. (1927). Amer. J. Dis. Child.. 33, 259.

Pinkerton, H. (1927). Amer. J. Dis.

(1928). Arch. Pathol. 5, 380.

Vaux, D. M. (1943). J. Path. Bact., 55, 93 . 691

Young, A. M., Applebaum, H. S., and Wasserman, P. B. (1939). J. Amer. med. Ass., 112, 2406.

\section{TERATOMA OF TESTIS SPONTANEOUS DISAPPEARANCE OF LUNG METASTASES}

BY

\section{J. EWART SCHOFIELD, F.R.C.Ṣ.}

Swindon, Wilts.

[With Photogravure Plate]

The following report of a case which showed evidence of the spontaneous disappearance of lung metastases will be of interest.

\section{Case Report}

In September, 1941, a youth aged 16 was referred to me by Dr. A. Gibson with a swelling of the right testicle. It was the size of a Jaffa orange, heavy, painless, but slightly tender. The cord was thickened. There was an indefinite swelling in the upper abdomen. The Wassermann reaction was negative. The radiologist's report on an $x$-ray examination of the chest read as follows: "Multiple, circular, sharply defined opacities in both lungs. They are of varying sizes, and are largest and most numerous in the lower zones. Intermediate sizes are seen in the mid-zones. There is no surrounding lung reaction around these opacities, the appearance of which is typical of secondary malignant deposits. There is no evidence of tuberculosis. The mediastinal glands are not enlarged." (Plate, Fig. 1.) A diagnosis of malignant testicular tumour with abdominal and lung metastases was made, and, in view of the metastases, the boy's parents were told that operation was not advised and that the expectation of life was only a few months.

In July, 1945, almost four years later, he was referred to me again by Dr. Gibson, who wished to know why the patient was still alive. Indeed, I was extremely surprised to see him myself, and, so far as I could remember, his general appearance had improved. Dr. Gibson stated that during the last four years the testicular tumour had varied considerably in size from that of a duck's egg to a Jaffa orange. The 'tumour of the right testis felt softer, was slightly fluctuant, and was a little larger than in 1941. An indefinite abdominal mass could still be felt. The $x$-ray appearance of the lungs was rather startling. The radiologist reported: "The only abnormality seen is a small round opacity in the left lower zone. In view of the previous $r$-ray appearance this shadow should be presumed to be a metastasis. The complete disappearance of all the other metastases is remarkable."

It was now considered justifiable to advise surgical treatment, and a right orchidectomy was performed, the cord being divided at the internal abdominal ring. Under the anaesthetic a definite mass of abdominal glands was palpated. Macroscopically the testicle had the appearance of a breaking-down tumour, yellowish in colour, with many cysts and cartilaginous nodules. The report of the pathologist on a microscopical section of the tumour, read: "The tumour appears to be a teratoma of the testicle, surrounded by a fairly dense fibrous capsule. The structure includes various tissues, the most prominent being cyst-like spaces of various sizes, lined with columnar or flattened epithelium. Nodules of cartilage are also present, embedded in the stroma, which is composed of loose fibrous tissue containing fibres of smooth and striped muscle. There are some masses of undifferentiated cells, suggestive of a malignant element. which is common in this type of tumour. It is considered, moreover, that all such testicular teratcmata are-potentially malignant, and should be treated accordingly."

The operation and convalescence passed off without incident, after which the patient's general condition improved, with increase of appetite and weight. The last report of the radiologist on a recent skiagram of the chest states that there is "no evidence of abnormality." (Plate, Fig. 2.) Despite frequent examination of the abdomen it is difficult to say whether the abdominal mass has completely disappeared.

The unorthodox course of the disease led me to inquire carefully into the patient's habits, occupation, diet, etc., after I first saw him in 1941 and pronounced the case inoperable. It appears that he was employed in a bakery until February, 1942, after which he obtained work in an aeroplane factory for twelve months. Here he breathed an atmosphere containing duralumin dust. From January, 1943, until July, 1945, he did casual work on a farm. He had no peculiar habits or liking for any particular article of diet.

Discussion
It is not intended here to expound on the subject of teratoma of the testis, for the literature on the subject is voluminous. The salient feature of the case described is that the lung metastases disappeared spontaneously. One hears from time to time of the spontaneous disappearance of malignant tumours, but the disappearance of secondary deposits in the lungs must be a rare occurrence. Saleeby (1944) quotes two cases of teratoma of the testis with metastases which recovered, but only after treatment. The treatment consisted of removal of both testicles, for Saleeby wondered if there was a relation between sex hormones and cancer, and thought that some carcinogenic agent is influenced by removal of both testes. One case, his own, was a patient who had a teratoma of the left testis, with a large metastatic retroperitoneal mass. $\mathrm{He}$ was treated by bilateral orchidectomy, supplemented by deep $x$-ray therapy. The patient was well after fourteen months, and the retroperitoneal mass had disappeared. The other case quoted by Saleeby was Dr. McClelland's, in which lumbar and lung metastases disappeared within twelve months of bilateral orchidectomy. This treatment was followed up by Harrison (1944), who treated three more cases of teratoma of the testis by bilateral orchidectomy and deep $x$-ray therapy. Reporting these cases, he stated that two of these patients died and the third was rapidly approaching dissolution. Harrison sums up by saying that "there is no clinical evidence to show that the course of the disease was affected by the operation."

In my own case it will be noted that the lung metastases disappeared before the primary growth was removed, and that deep $x$-ray therapy was not given-in fact, there was no treatment of any description. It was only after observing the disappearance of lung metastases that it was decided io remove the tumour of the testicle.

In discussing this subject one cannot fail to draw a comparison with chorio-epithelioma. In this disease a number of cases are known in which lung metastases have disappeared, but only after removal of the primary growth by hysterectomy. Teacher (1935) mentions cases in which 


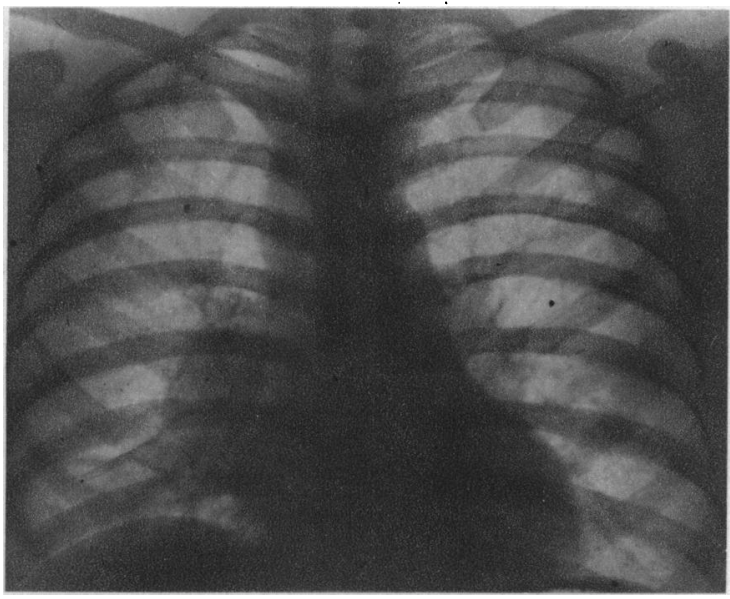

Fig. 1.-On first admission (July, 1945).

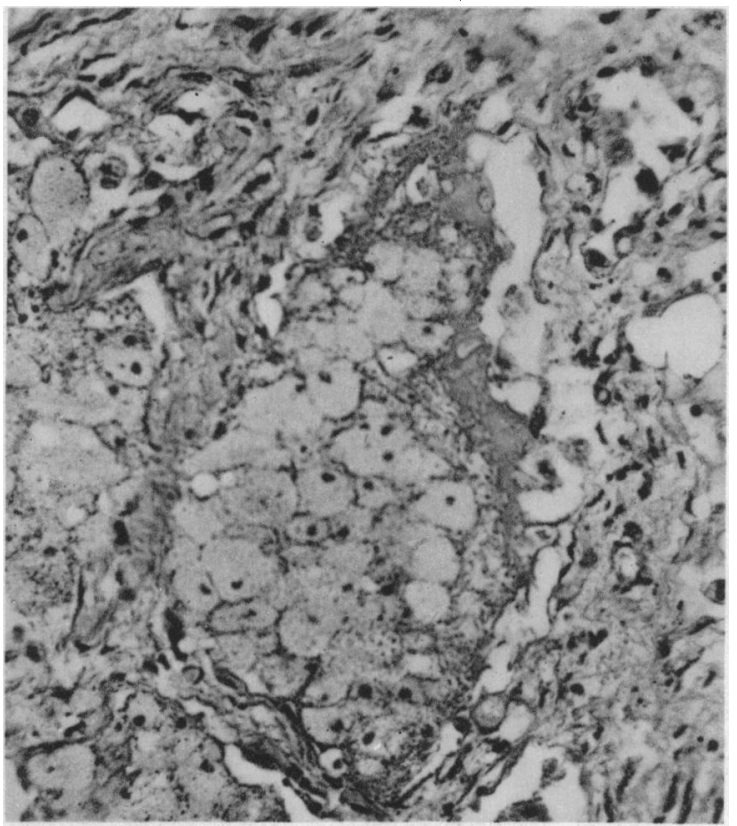

FIG. 3.-Lung $(\times 250)$ showing foamy macrophages in alveolus.

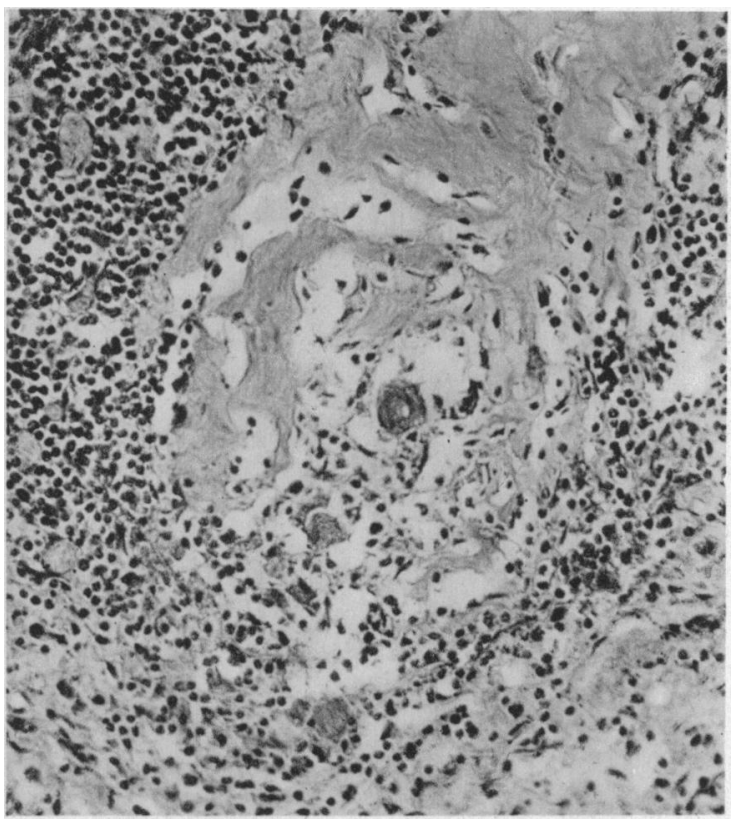

FIG. 5.-Mediastinal lymph node $(\times 250)$ showing area of fibrosis with "foreign body" giant cells.

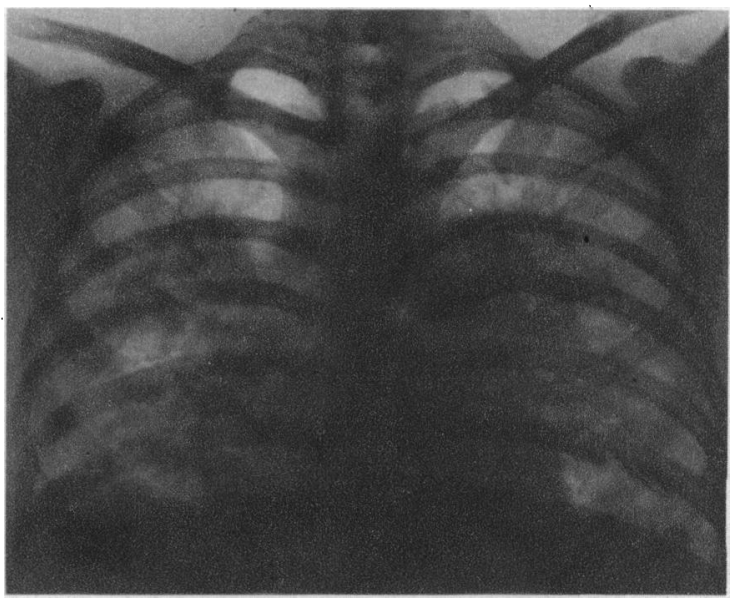

Fig. 2.-Shortly before death (May, 1946).

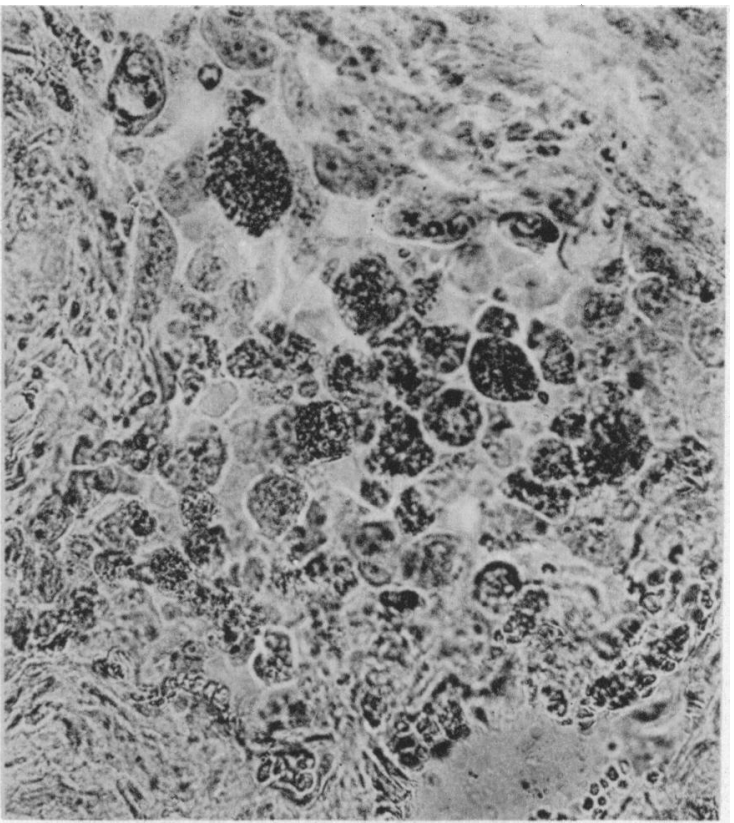

FIG. 4.-Lung $(\times 250)$, stained with Scharlach $R$, showing fat globules within the macrophages.

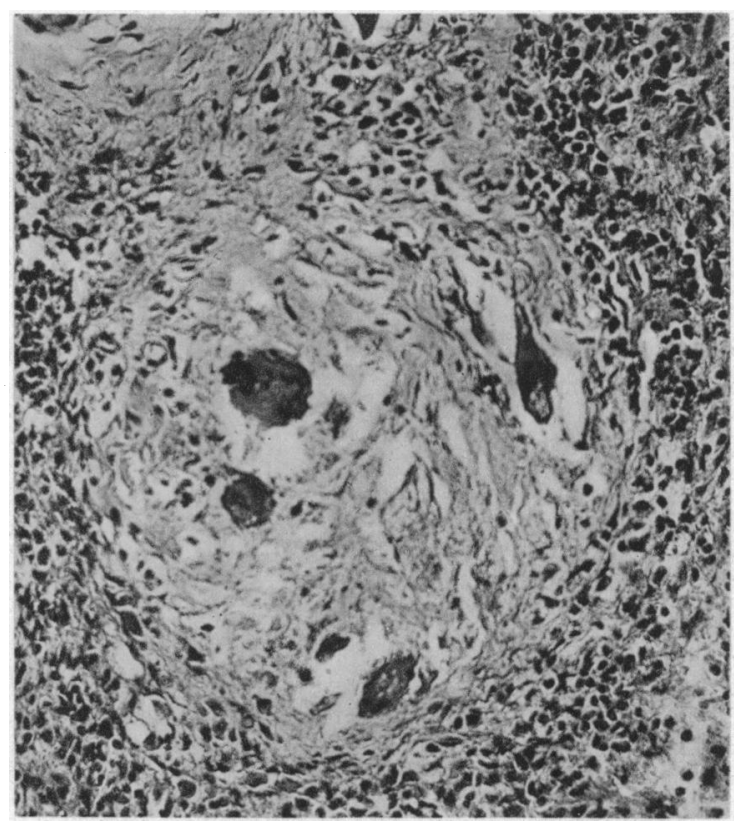

FIG: 6. - Spleen $(\times 250)$ showing area of fibrosis as in Fig. 5. 


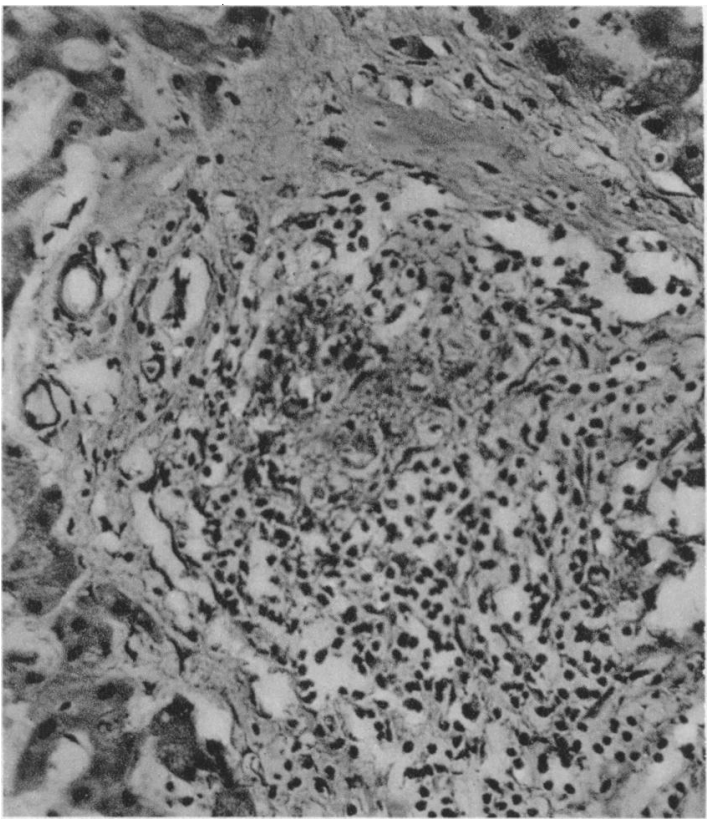

Fig. 7.- - Liver $(\times 250)$ showing area of fibrosis as in Figs. 5 and 6.

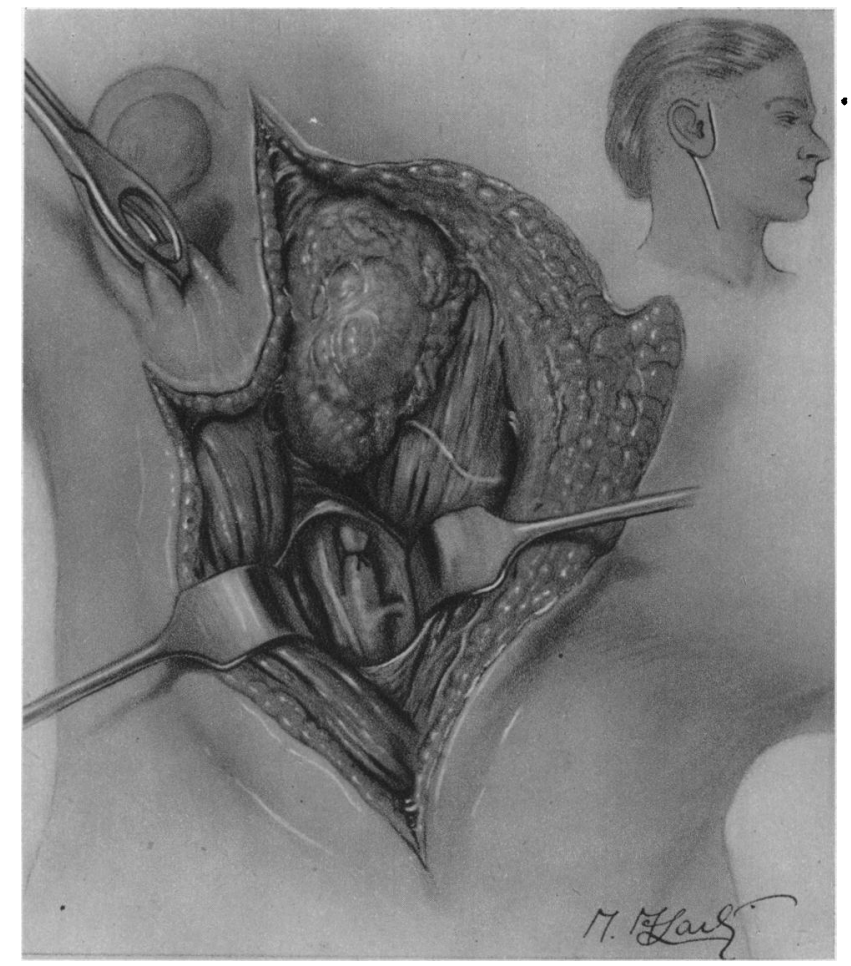

FIG. 1.

Fig. 1.-Exposure of the whole gland and ligation of the external carotid artery.

Fig. 2.-Excision of the superficial lobe. Note the temporo-facial division of the seventh nerve.

FIG. 3.-Extracapsular resection of a tumour in the superficial lobe of the parotid gland.

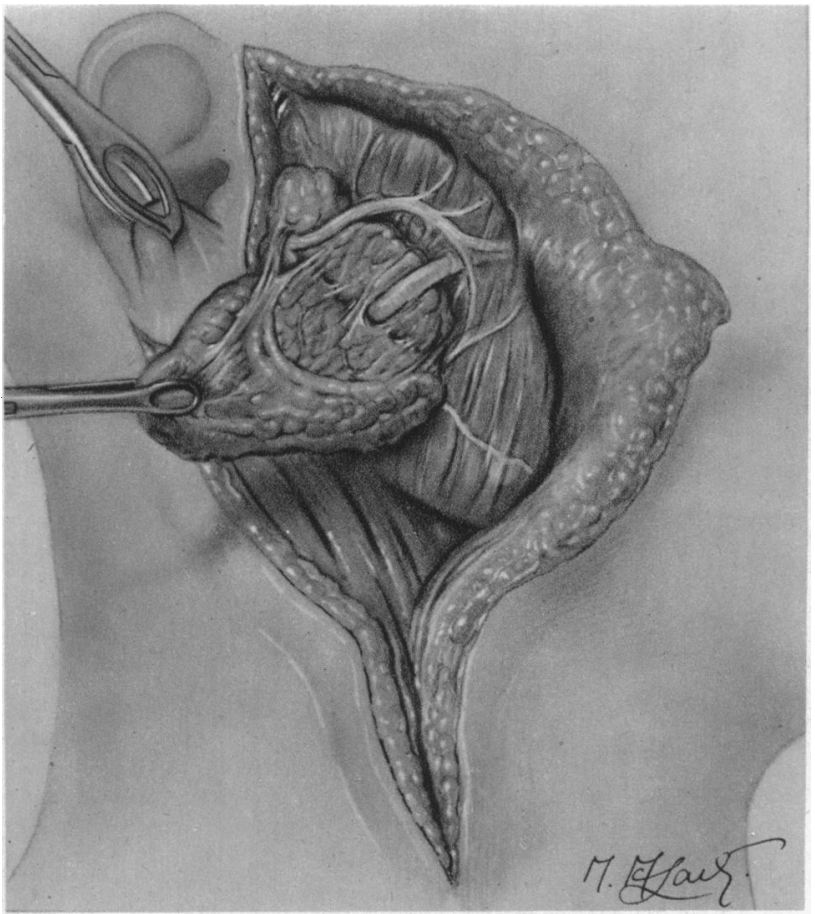

FIG. 2.

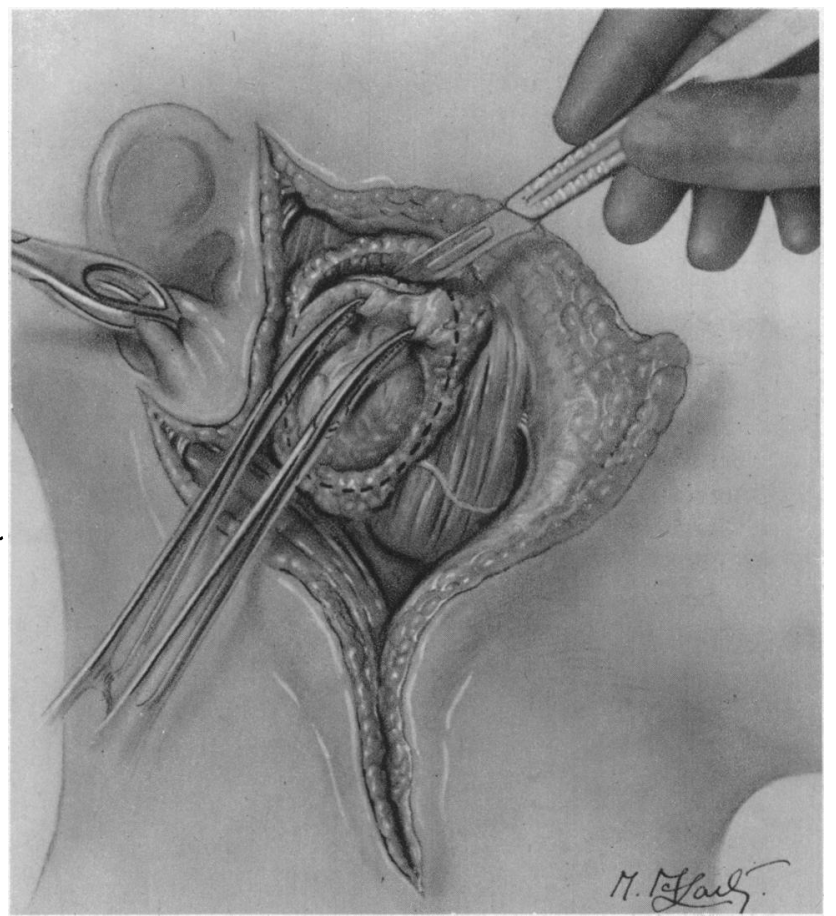

FIG. 3. 